\title{
A CONSTITUIÇÃO DA EDUCAÇÃO INFANTIL NOS DOCUMENTOS OFICIAIS BRASILEIROS
}

Laíza Kamila dos Santos Silva, Universidade Federal de Campina Grande (UFCG), laysa_kamilla@hotmail.com

Manoela da Silva Brito, Universidade Federal de Campina Grande (UFCG), manoella_93@hotmail.com

Dorgival Gonçalves Fernandes, Universidade Federal de Campina Grande (UFCG), dorgefernandes@yahoo.com.br

\section{RESUMO}

O presente artigo, objetiva analisar a constituição da educação infantil a partir de documentos emitidos pelo Ministério da Educação, outros documentos oficiais e programas, centrando-se nas leis no período de 1988 a 2010. O estudo dos documentos e programas, para o qual contamos com a leitura de teóricos, a exemplo de Corsino, Santos e Nunes. Evidenciou-se que no período analisado aconteceram mudanças fundamentais aos direitos da criança.

PALAVRAS - CHAVE: Educação infantil. Documentos oficiais. Formação de professores.

\section{THE CHILDHOOD EDUCATIONCONSTITUTION IN THE OFFICIAL BRAZILIAN DOCUMENTS}

\begin{abstract}
This article aims to analyze the constitution of children's education from documents issued by the Ministry of Education, other official documents and programs, focusing on laws from 1988 to 2010. The study of the documents and programs, for which we are based with theories of Corsino, Santos and Nunes.Evidenced that in the analyzed period fundamental changes happened in the rights of the child.

Keywords: Childhood Education. Official Documents. Teachers Formation.
\end{abstract}




\section{RESUMEN}

El presente artículo tiene como objetivo analizar la constitución de la educación infantil a partir de documentos emitidos por el Ministerio de Educación, otros documentos oficiales y programas, centrándose en las leyes en el período de 1988 a 2010. El estudio de los documentos y programas, para el que contamos Con la lectura de teóricos, a ejemplo de Corsino, Santos y Nunes, evidenció que en el período analizado se produjeron cambios fundamentales a los derechos del niño.

PALABRAS - CLAVE: Educación infantil. Documentos oficiales. Formación de profesores.

\section{INTRODUÇÃO}

A educação brasileira, nos seus diversos níveis e modalidades, é regida por uma base legal expressa por documentos oficiais. Tais documentos, desse modo, são elementos constituintes da educação. É neste sentido que no presente artigo objetivamos pensar a constituição da educação infantil no Brasil entre os anos 1988 a 2010. Por centrar-se na análise de documentos, a pesquisa que embasa este artigo caracteriza-se como pesquisa documental. Mas também como pesquisa bibliográfica, haja vista que para entendermos melhor a questão da educação infantil no período estudado, recorremos aos estudos de teóricos que pensam a educação infantil e que se ocuparam da análise de documentos que elencamos para o estudo.

A Legislação Brasileira refere-se aos direitos constitucionais do cidadão e a educação é um desses direitos. Neste sentido, a educação infantil também é um direito assegurado, destinado ao sujeito criança de 0 a 05 anos, devendo ser efetivado com a sua matrícula em creches e pré-escolas.

$\mathrm{Na}$ intenção de verificarmos como a educação infantil vem sendo constituída no âmbito legal, analisamos os seguintes documentos: Estatuto da Criança e do Adolescente ECA (1990), Lei de Diretrizes e Bases da Educação Nacional - LDB (1996), Plano Nacional de Educação - PNE (2001), Diretrizes Curriculares Nacionais para a Educação Infantil DCNEI (2010), e alguns programas, tais como o Programa de Formação Inicial para professores em Exercício na Educação Infantil - Proinfantil (2005) e o Fundo de Manutenção 
e Desenvolvimento da Educação Básica e de Valorização dos Profissionais da Educação FUNDEB (2006).

A Constituição Brasileira de 1988 estabelece em seu Art. 280 o dever do Estado para com a educação, e neste, no inciso IV, se refere à educação infantil, afirmando que essa deve ser ofertada em creche e pré-escola, às crianças até 5 (cinco) anos de idade, afirmando que, segundo reza o Art. 211, § $2^{\circ}$, Os Municípios atuarão prioritariamente no ensino fundamental e na educação infantil. É a partir desse dispositivo legal que será socialmente discutido e ordenado o campo da educação infantil, vivenciando este campo, desde então, intenso processo de revisão e reformulações das concepções acerca do sujeito criança, da infância e da educação de infantil tendo-se como referente às políticas públicas, os sentidos e fins educacionais, as práticas pedagógicas e, consequentemente, a formação e a valorização dos profissionais da educação infantil.

\section{A CONSTITUIÇÃO DA EDUCAÇÃO INFANTIL NOS DOCUMENTOS LEGAIS PÓS 1988}

A Constituição Federal de 1988, conforme assinala Santos (2008, p.23), “ampliou imensamente a gama de direitos individuais e coletivos, garantindo proteção à família, às crianças e ao adolescente, ao idoso, ao índio". E especificamente em relação à educação infantil, Nunes (2011, p.8) aponta que essa Constituição

traz como característica a ênfase no estabelecimento de políticas públicas universais, a concepção de educação como um direito de todas as crianças desde o nascimento e a concepção de criança cidadã, sujeito de direitos, cujo desenvolvimento e indivisível. Estabelece como dever do Estado garantir a educação de 0 a 5 anos de idade, no sistema formal institucional, e afirma a educação infantil como a primeira etapa da educação básica.

A garantia da educação formal às crianças tem como eixos norteadores o cuidar e o educar, tendo por objetivo primeiro seu desenvolvimento integral. Os documentos promulgados a partir da Constituição Federal reforçam cada vez mais e de modo mais efetivos os direitos que a criança adquire a partir do seu nascimento, bem como a consideração da sua condição infantil na sua especificidade e singularidade. Tal fato é fundamental para a 
constituição da educação infantil, haja vista que no Brasil, por muito tempo, as crianças foram tratadas como adultos em miniaturas, e neste sentido, a nossa Lei Magna, chamada pelo presidente da Assembléia Nacional Constituinte de "Constituição Cidadã" retirou as crianças e vários outros grupos da situação de excluídos da sociedade. Assim, "redefiniu os princípios da República e restabeleceu o Estado de Direito" (NUNES, 2011, p. 30).

Nesta perspectiva, a educação infantil como a primeira etapa da educação básica tem a função de desenvolver e socializar a criança de 0 a 5 anos a partir da sua concepção como sujeito de direitos. Nas palavras de Alves (2011, p.11):

As novas concepções de criança, baseados nas múltiplas áreas do desenvolvimento e na condição de sujeito ativo e de direito, indicam que a educação da criança deve promover a aprendizagem considerando a integralidade e a indivisibilidade das dimensões do seu desenvolvimento.

O Estatuto da Criança e do Adolescente (ECA), de 1990, se instituiu como o estatuto jurídico da criança cidadã, é o documento que dispõe sobre a proteção integral à criança e ao adolescente, reforçando assim a cidadania conquistada pelas crianças. Segundo Nunes (2011, p.32):

Ele consagra uma nova visão da criança e do adolescente na sociedade brasileira, afastando o olhar autoritário, paternalista, assistencialista e repressivo do Código de Menores e coloca, no lugar dele, o da criança cidadã, sujeito de direitos, em processo de desenvolvimento e formação. Adota a doutrina da proteção integral em oposição ao princípio da situação irregular.

Com o ECA, as crianças e os adolescentes, na letra da lei, passaram a ser reconhecidos como sujeitos de direitos, seus direitos devem ser tratados com prioridade absoluta. Este estatuto estabelece que a família, o Estado e a sociedade são responsáveis pela sua proteção a partir da consideração de que são cidadãos que estão vivendo um período de intenso desenvolvimento físico, psicológico, moral e social. Ele reforça a definição de que a educação escolar é fundamental para o desenvolvimento de toda criança. Cabe ressaltar no tocante à proteção e à educação da criança a coibição de castigos físicos estabelecida por esse estatuto, 
no seu Art. 18, colidindo com determinada cultura educativa brasileira que emprega castigos físicos como meio educativo.

Na Lei de Diretrizes e Bases da Educação Nacional (LDB), de 1996, a educação infantil é também reconhecida como importante para o desenvolvimento da criança e definida como a primeira etapa da educação básica, tendo a finalidade de desenvolver integralmente a criança de até seis anos de idade, em seus aspectos físico, psicológico, intelectual e social, com a complementaridade da ação familiar e da comunidade. (BRASIL, 1996). Um aspecto importante deste documento se refere à questão da formação dos profissionais da educação infantil, determinando uma formação mínima e específica para aqueles que trabalharão com o cuidado e a educação das crianças. Reza esse documento (BRASIL, 1996), em seu Art. 62:

A formação de docentes para atuar na educação básica far-se-á em nível superior em curso de licenciatura, de graduação plena, em universidades e institutos superiores de educação, admitida, como formação mínima para o exercício do magistério na educação infantil e nos 5(cinco) primeiro anos do ensino fundamental, a oferecida em nível médio na modalidade normal.

É perceptível que entre um documento e outro houve um progresso em relação à concepção e determinação quanto à formação de professores da educação infantil. Esta passou a ter na LDB a regulamentação da exigência mínima para a atuação dos docentes e a especificidade de determinados procedimentos pedagógicos, como é o caso da avaliação da aprendizagem ou do desenvolvimento infantil. Nessa perspectiva, de acordo com Santos (2008), no artigo 31 da LDB, o processo avaliativo da Educação Infantil deve ser feito através de acompanhamento e registro de desenvolvimento de cada aluno sem o objetivo de seleção, promoção ou classificação. O aluno deve ser avaliado de maneira gradativa em vista da sua evolução dentro do seu contexto educacional, mas também pessoal e contextual, levando-se em consideração a singularidade de cada criança.

A Resolução $\mathrm{n}^{\circ}$ 5, de 17 de dezembro de 2009, fixa as Diretrizes Curriculares Nacionais para a Educação Infantil com o propósito de garantir às crianças o acesso aos conhecimentos da aprendizagem e proporcionar o direito a brincadeiras e convivência na interação com outras crianças como direito social, como premissa orientadora da elaboração de políticas públicas, planejamentos, execuções e avaliações de propostas pedagógicas e curriculares de educação infantil devendo ser observadas em consonância com as legislações 
estaduais e municipais, apresentando orientações pedagógicas que sejam respaldadas em princípios éticos, estéticos e políticos em conformidade com a condição da criança como sujeito de direitos.

Há um pouco mais de dez anos, após a criação da LDB 1996, a Educação Infantil é incluída no Fundo de Manutenção e Desenvolvimento da Educação Básica e de Valorização dos Profissionais da Educação (FUNDEB), a partir do qual começa a receber financiamento para atender as suas demandas, tornando-se mais um meio para se efetivar a abertura de novas creches e pré-escolas e o melhoramento das existentes através de medidas políticopedagógico-administrativas dos sistemas municipais que têm responsabilidades constitucionais pela educação infantil. Neste caso, ainda que não tenha havido ainda o atendimento de toda demanda social por educação infantil, não se pode deixar de reconhecer a sua expansão. Porém, como assinala Corsino (2012, p.2):

Para atender a essa expansão da educação infantil, são necessárias estudos, reflexões e articulações entre teoria e prática, formação de professores, construção e adequação de espaços, aquisição de equipamentos e materiais, organização de rotinas, elaboração de planejamento, entre outras demandas.

O Plano Nacional de Educação (PNE), de 2001, trata-se de um conjunto de metas político-pedagógicas. Este tem um capítulo que enfatiza a educação infantil em creches e préescolas de forma comum. Constitui-se como um avanço no processo de aprendizado, passando a ter novas visões sobre propostas pedagógicas. O plano aponta que se deve ter uma expansão da educação infantil de forma ampla e com qualidade. São metas estruturantes para garantir o direito a educação básica com qualidade, e que assim promovam a garantia do acesso ao ensino obrigatório e a ampliação das oportunidades educacionais.

É objetivo que todas as instituições que ministram a educação infantil façam do processo educativo o meio de desenvolvimento integral das crianças de 0 a 5 anos, exercitando-o através das relações que as crianças estabelecem entre si e com os profissionais que atuam nesta área educativa. Assim, aos diferentes profissionais da Educação Infantil que atuam devem exercer diferentes funções educativas, cabendo-lhes a importante e complexa tarefa de ampliar a experiência da criança no processo de desenvolvimento infantil. Todavia, os avanços conquistados em relação à condição da criança como sujeito de direitos e à abrangência da sua educação tem se deparado com o problema da qualificação dos 
profissionais, ou seja, a maioria não possui formação profissional efetiva. No caso, esta função acaba sendo desempenhada por profissionais diversos sem a formação necessária, tais como: babás, estagiários etc. A formação inicial do profissional da educação infantil deve ser iniciada nos cursos de licenciatura em Pedagogia ministrado por universidades ou institutos, centros universitários, faculdades, cabendo, para essa formação inicial, também o curso normal superior. Tal formação deve ser complementada pelo exercício prático no desempenho profissional, possibilitando que os profissionais ampliem seus conhecimentos e habilidades de modo crítico refletindo sobre suas ações. Nessa perspectiva, é importante salientar, se faz necessária a valorização social e econômica desses profissionais, por parte do governo e da sociedade civil para que a tarefa de educar, de modo coerente com as concepções e os princípios da educação infantil, seja desenvolvida.

Infelizmente, a problemática situação da formação de muitos profissionais da educação infantil produz um trabalho muitas vezes desprovido de planejamento eficaz e sem coerência com os objetivos oficialmente definidos. Sobre o profissional docente da educação infantil, Garanhani (2010, p.196) faz a seguinte abordagem:

Ser docente na Educação Infantil, com base no perfil apresentado, é ter sempre uma atitude investigativa da própria prática e, conseqüentemente, fazer a sua elaboração por meio de um processo contínuo de formação. É ter o compromisso com a profissão escolhida e consciência de que suas intenções e ações contribuem na formação humana de nossas crianças ainda pequenas. Formação humana que se faz pelo acesso aos saberes, conceitos e práticas de nossa sociedade e que se apresentam como ferramentas de trabalho, pelo respeito às condições de aprendizagem que se faz pela oferta de possibilidades educacionais e, por fim, a clareza de que a professora da pequena infância é uma das profissionais responsáveis por proporcionar a conquista da autonomia e da construção de identidades das crianças pequenas do nosso país.

Na perspectiva de alcançar as metas do PNE e executar as determinações da LDB em relação à formação dos professores, o Ministério da Educação criou o Programa de Formação Inicial para Professores em Exercício na Educação Infantil (Proinfantil). Segundo Corsino (2010), o Proinfantil é um curso semipresencial de formação em ensino médio, oferecido aos professores em exercício nas redes municipais e estaduais de ensino, com duração de 2 anos e com direito a diploma para exercer a função docente na educação infantil em creches e pré escolas. 
A educação infantil cada vez mais sofre mudanças em sua concepção em espaços institucionais - não domésticos - e com isso o trabalho pedagógico requer do profissional habilidade que vai além do cuidar, haja vista que, conforme saliente Angotti (2010, p. 28):

A Educação Infantil enquanto etapa da Educação Básica, parte pertencente ao sistema brasileiro, não pode mais aceitar a manutenção de paradigmas que ofereçam apenas atendimento assistencial às crianças; que cuidem no sentido da mera proteção, higiene alimentação sem educá-las; que acreditam que o fortalecimento da coordenação motora fina e a pretensão de antecipação de alfabetizar no sentido estrito da leitura e da escrita sejam o papel suficiente e adequado do atendimento proposto; nem tampouco pode desconsiderar e abrir mão de conquistas alcançadas até aqui, sobretudo do ponto de vista de legislação existente.

Esta preocupação apresentada por Angotti pode ser respaldada nas palavras de Corsino quando este afirma: "As mudanças de concepções de infância e de educação infantil ocorridas nas últimas décadas trazem implicações tanto no âmbito das políticas, quanto do cotidiano da escola" (2010, p.6). A educação infantil, a partir das efetivas mudanças históricas quanto a sua concepção e organização, ampliou seu espaço no âmbito educacional sendo alvo de reflexões e debates a favor da garantia do seu espaço na educação como primeira etapa da educação básica, assumindo uma identidade própria e singular. É essa identidade própria e singular que marca a constituição da educação infantil no Brasil após o ano de 1988 e tem animado o debate e as lutas em prol da sua extensão para atender a grande demanda social e aperfeiçoar a sua concepção e operacionalidade.

\section{CONSIDERAÇÕES FINAIS}

Tendo em vista o que foi por nós exposto e analisado quanto à educação infantil, depreende-se que os documentos sancionados no período após o ano de 1988, iniciado com a inserção da educação infantil na Constituição Federal como primeira etapa da educação básica, vem ampliando o asseguramento ao público da educação infantil em creches e préescolas os seus direitos, tornando tal etapa como fundamental no processo educativo. Porém, se faz necessário que os documentos que oficializam esses direitos enfatizem a necessidade de uma melhor formação para os profissionais que atuam e atuarão na educação infantil. A 
análise dos documentos elencados para este estudo nos mostra que em alguns desses não há propostas efetivas que tratem com mais afinco a formação desses profissionais, fato esse que nos traz preocupação, haja vista a necessidade de ampliação dos seus conhecimentos e habilidades para dar materialidade aos avanços conquistados na constituição da educação infantil em termos de concepção e de políticas para a sua operacionalização.

\section{REFERÊNCIAS}

ALVES, Bruna Molisani Ferreira. Infâncias e educação infantil: aspectos históricos, legais e pedagógicos. Revista Aleph infâncias. Rio de janeiro, 2011.

ANGOTTI, Maristela ( $\left.\operatorname{org}^{\mathrm{a}}\right)$. Educação infantil: para que, para quem e porquê. 3. Ed. Campinas, SP: Editora Alínea, 2010.

BRASIL. Ministério da Educação. Secretaria de Educação Básica. Diretrizes curriculares nacionais para educação infantil. Brasília: MEC, SEB, 2010.

Conselho Nacional de Educação. Câmara de Educação Básica. Revisão das Diretrizes Curriculares Nacionais para Educação Infantil. Parecer n 20/2009. Brasília, DF, 09 de dezembro de 2009, Seção 1, p. 14.

Constituição da República Federativa do Brasil. Brasília, DF: Senado Federal: Centro Gráfico, 1988. Acesso em:

http://www.cairu.br/biblioteca/arquivos/Direito/Constituicao_da_Republica_Federativa_Brasi l.pdf

Estatuto da criança e do adolescente: Lei federal $n^{\circ}$ 8069, de 13 de julho de 1990. Rio de Janeiro: Imprensa Oficial, 2002. Acesso em: http://www.crianca.mppr.mp.br/arquivos/File/publi/camara/estatuto_crianca_adolescente_9ed .pdf 
Plano Nacional de Educação. Brasília: Senado Federal, Unesco, 2001. Acesso em: http://unesdoc.unesco.org/images/0013/001324/132452porb.pdf

CORSINO, Patrícia, (org.). Educação infantil: cotidiano e políticas. Campinas, SP: Autores Associados, 2012. - (Coleção educação contemporânea)

FARIA, V.; SALLES, F. Currículo na Educação Infantil. São Paulo: Scipione, 2010.

NUNES, Maria Fernanda Rezende. Educação infantil no Brasil: primeira etapa da educação básica. Brasília: UNESCO, Ministério da Educação/Secretaria de Educação Básica, Fundação Orsa, 2011.

OLIVEIRA, Zilma de Moraes Ramos de. Educação Infantil: fundamentos e métodos. - 6. Ed. - São Paulo: Cortez, 2010. - (Coleção Docência em Formação)

SANTOS, Clóvis Roberto dos. Direto à educação: a LDB de A a Z São Paulo: Avercamp, 2008. 